\title{
The Impact of Chitosan on the Chemical Composition of Wines Fermented with Schizosaccharomyces pombe and Saccharomyces cerevisiae
}

\author{
Stefano Scansani $\left.{ }^{1}{ }^{(}\right)$, Doris Rauhut ${ }^{1}$, Silvia Brezina ${ }^{1}$, Heike Semmler ${ }^{1}$ and Santiago Benito ${ }^{2, *(\mathbb{C}}$ \\ 1 Department of Microbiology and Biochemistry, Hochschule Geisenheim University (HGU), \\ Von-Lade-Straße 1, 65366 Geisenheim, Germany; stefano.scansani@hs-gm.de (S.S.); \\ doris.rauhut@hs-gm.de (D.R.); silvia.brezina@hs-gm.de (S.B.); heike.semmler@hs-gm.de (H.S.) \\ 2 Department of Chemistry and Food Technology, Polytechnic University of Madrid, \\ Ciudad Universitaria S/N, 28040 Madrid, Spain \\ * Correspondence: santiago.benito@upm.es; Tel.: +34-910671107
}

Received: 29 August 2020; Accepted: 3 October 2020; Published: 9 October 2020

\begin{abstract}
This study investigates the influence of the antimicrobial agent chitosan on a selected Schizosaccharomyces pombe strain during the alcoholic fermentation of ultra-pasteurized grape juice with a high concentration of malic acid. It also studies a selected Saccharomyces cerevisiae strain as a control. The study examines several parameters relating to wine quality, including volatile and non-volatile compounds. The principal aim of the study is to test the influence of chitosan on the final chemical composition of the wine during alcoholic fermentation, and to compare the two studied fermentative yeasts between them. The results show that chitosan influences the final concentration of acetic acid, ethanol, glycerol, acetaldehyde, pyruvic acid, $\alpha$-ketoglutarate, higher alcohols, acetate esters, ethyl esters, and fatty acids, depending on the yeast species.
\end{abstract}

Keywords: wine; aroma compounds; Schizosaccharomyces; chitosan; higher alcohols; esters; fatty acids; malic acid; Saccharomyces

\section{Introduction}

Schizosaccharomyces pombe is an interesting alternative to Saccharomyces cerevisiae for de-acidifying grape juices with a high malic acid content [1-3] or other fruit juices with similar acidity problems [4-7]. However, yeasts of the genus Schizosaccharomyces often produce undesirable effects during alcoholic fermentation, such as a high volatile acidity over $1 \mathrm{~g} \mathrm{~L}^{-1}[6,8]$ and high acetaldehyde production over $125 \mathrm{mg} \mathrm{L}^{-1}[4,9]$. They also usually require longer fermentation times than Sac. cerevisiae $[2,6]$.

In recent years, several authors have reported efforts to optimize the biotechnology of fermentation with Sch. pombe so as to avoid these undesirable effects. A combined inoculation with Sac. cerevisiae has enabled a reduction in the final concentration of the volatile acidity [2]. Several researchers have reported similar effects for combined fermentations with Lachancea thermotolerans [10-13] and Torulaspora delbrueckii [4]. Because of the high strain variability in parameters such as volatile acidity, which varies from 0.24 to $1.12 \mathrm{~g} \mathrm{~L}^{-1}$ [2], or acetaldehyde, which varies from 17 to $134.14 \mathrm{mg} \mathrm{L}^{-1}[2,4,9]$, it is possible to select small numbers of Schizosaccharomyces strains that do not exhibit these undesirable effects. Fed-batch fermentation technology with $S c h$. pombe allows for reducing acetic acid production during alcoholic fermentation by up to $100 \%$, and leads to a $50 \%$ reduction in acetaldehyde production [14,15].

Other than deacidification, modern applications for Sch. pombe in fermentative industries include improvements in wine color [2], increased production of polysaccharides [9,16,17], and use as an aid to control food safety risks such as biogenic amines or ethyl carbamate $[18,19]$. 
The slower fermentation kinetics of Sch. pombe compared with those of Sac. cerevisiae often increase the risk of contamination at an industrial scale. The kinetics are even slower for fermentation at low temperatures [2], such as in the north of Europe. The antioxidant and antimicrobial agent sulfur dioxide usually solves the problems related to undesirable microbial contaminations during alcoholic fermentations involving Sac. cerevisiae. However, Sch. pombe is highly resistant to sulfur dioxide because its defense mechanisms is based on increasing the production of acetaldehyde, which combines with sulfur dioxide to inactivate the effect of its free form. Aditionally, it is also able to metabolize sulfur dioxide to sulfhydric acid reducing its effective concentration [2]. Thus, the use of antioxidant and antimicrobial agents other than sulfur dioxide could avoid the formation of these undesirable compounds during alcoholic fermentation with Sch. pombe.

Chitosan is a powerful antioxidant and antimicrobial [20-24] agent. It is becoming popular in winemaking because of a trend towards lowering the legal limit of sulfur dioxide in wines [18]. However, some studies report that chitosan has a lower antimicrobial effect compared with sulfur dioxide [25]. While there is evidence of the effect of chitosan on the fermentation kinetics of different yeast species [21], its influence on the final aroma composition remains unstudied. The present study explores the influence of chitosan on Sch. pombe alcoholic fermentation for the first time.

\section{Experimental Section}

\subsection{Microorganisms}

The Sac. cerevisiae strain Lalvin QA23 ${ }^{\circledR}$ (Lallemand, Montréal, QC, Canada) was the control sample for the vinification because of its rapid fermentation performance and high tolerance to low temperatures. The Sch. pombe strain V2 [10] possess a high rate of malic acid degradation and a low rate of acetic acid production.

\subsection{Vinification}

All of the fermentations used ultra-pasteurized (UHT) white grape juice (Jacoby GmbH, Auggen, Germany;). The amount of malic acid was adjusted by adding L-(-)-malic acid (Sigma Aldrich, Darmstadt, Germany), whereas the sugar level was adjusted by adding a mixture of D-glucose and D-fructose in an equal ratio (1:1; Merck KGaA, Darmstadt, Germany). The nitrogen level was adjusted by adding $0.4 \mathrm{~g} \mathrm{~L}^{-1}$ of Fermaid E Blanc (Danstar Ferment AG-Lallemand Inc., Fredericia, Denmark) and $0.4 \mathrm{~g} \mathrm{~L}^{-1}$ of OptiMUM white (Danstar Ferment AG-Lallemand Inc., Zug, Switzerland). The starting chemical parameters of the must after the adjustment were as follows: sugar $191.2 \mathrm{~g} \mathrm{~L}^{-1}$; pH 3.26; yeast-assimilable nitrogen content (YAN) $262 \mathrm{mg} \mathrm{L}^{-1}$ (Primary Amino Nitrogen (NOPA): $115 \mathrm{mg} \mathrm{L}^{-1}$ and ammonia: $146 \mathrm{mg} \mathrm{L}^{-1}$ ); tartaric acid, $2.33 \mathrm{~g} \mathrm{~L}^{-1}$; malic acid $6 \mathrm{~g} \mathrm{~L}^{-1}$; citric acid $0.15 \mathrm{~g} \mathrm{~L}^{-1}$; lactic acid $<0.1 \mathrm{~g} \mathrm{~L}^{-1}$; and acetic acid $<0.1 \mathrm{~g} \mathrm{~L}^{-1}$. In two assays (SC_ch and SP_ch), $0.5 \mathrm{~g} \mathrm{~L}^{-1}$ of chitin-glucan and chitosan from Aspergillus niger origin were added following the manufacturer's instructions (Bactiless ${ }^{\mathrm{TM}}$, Danstar Ferment AG-Lallemand Inc., Fredericia, Denmark) so as to evaluate the effect on the final wine chemical composition of the different species.

Four assays were performed in triplicate according to a previously reported micro fermentation methodology [10] adapted to a $0.85 \mathrm{~L}$ scale, as follows: (1) inoculation of the must with Sac. cerevisiae QA23 (106 $\left.\mathrm{cfu} \mathrm{mL}^{-1}\right)$ alone (SC); (2) inoculation of the must with Sac. cerevisiae QA23 $\left(10^{6} \mathrm{cfu} \mathrm{mL}^{-1}\right)$ alone and $0.5 \mathrm{~g} \mathrm{~L}^{-1}$ of Bactiless ${ }^{\mathrm{TM}}$ (SC_ch); (3) inoculation of the must with Sch. pombe V2 $\left(10^{6} \mathrm{cfu} \mathrm{mL}^{-1}\right)$ alone (SP); and (4) inoculation of the must with Sch. pombe V2 $\left(10^{6} \mathrm{cfu} \mathrm{mL}^{-1}\right)$ alone and $0.5 \mathrm{~g} \mathrm{~L}^{-1}$ of Bactiless $^{\mathrm{TM}}$ (SP_ch). The yeast inocula were prepared using $100 \mathrm{~mL}$ of sterilized must with $1 \mathrm{~mL}$ of yeast extract peptone dextrose (YEPD) liquid medium containing about $10^{6} \mathrm{cfu} \mathrm{mL}^{-1}$ (determined using a Thoma chamber hemocytometer). To reach this population, $100 \mu \mathrm{L}$ of each yeast suspension was cultivated in $10 \mathrm{~mL}$ of YEPD at $25^{\circ} \mathrm{C}$ for $24 \mathrm{~h}$. This procedure was repeated three times before the final inoculation. The inoculations were performed in $250 \mathrm{~mL}$ sterile flasks sealed with a fermentation lock filled with an aqueous solution of $100 \mathrm{mg} \mathrm{L}^{-1}$ of total sulfur dioxide as potassium metabisulfite 
salt (Merck, Darmstadt, Germany), which allowed for the release of $\mathrm{CO}_{2}$ while avoiding microbial contamination. The temperature was maintained at $25^{\circ} \mathrm{C}$ for $48 \mathrm{~h}$. The development of the inocula was conducted without aeration, oxygen injection, or agitation.

All of the fermentation trials were carried out at $20{ }^{\circ} \mathrm{C}$ in a temperature-controlled room. The fermentation vessels were sealed with a fermentation lock filled with an aqueous solution of $100 \mathrm{mg} \mathrm{L}^{-1}$ of potassium metabisulfite (Merck, Darmstadt, Germany) that allowed for the release of $\mathrm{CO}_{2}$ while avoiding microbial contamination. The weight loss of the vessels during alcoholic fermentation was monitored using a scale model Kern FCB 12K1N (Kern and Sohn GmbH, Balingen, Germany). Once the weight loss remained constant for $48 \mathrm{~h}$, the wines were racked and stabilized for 7 days at $4{ }^{\circ} \mathrm{C}$, and the final product was bottled in $100 \mathrm{~mL}$ bottles. Potassium metabisulfite (Merck, Darmstadt, Germany) was then added to achieve a concentration of $80 \mathrm{mg} \mathrm{L}^{-1}$ total sulfur dioxide. The bottles were sealed with the headspace purged with nitrogen and were placed in a climate chamber at $4{ }^{\circ} \mathrm{C}$.

\subsection{Analytical Determinations}

A pH 526 pH-meter equipped with a SennTix 81 electrode (WTW, Waldböckelheim, Germany) was used to measure the $\mathrm{pH}$. Measurements of the non-volatile organic acids, ethanol, and residual sugars were performed by high-performance liquid chromatography (HPLC) according to Kanter et al., 2020 [26]. For the analyses of the esters, higher alcohols, and fatty acids, the method of the Department of Microbiology and Biochemistry of Hochschule Geisenheim University [27] was applied. The concentrations of acetaldehyde and pyruvate at the end of the fermentations were measured using specific enzymatic assays (K-ACHYD and K-PYRUV, Megazyme, Butzbach, Germany). The $\alpha$-ketoglutarate was measured according to the Bergmeyer and Gawehn method [28].

\subsection{Statistical Analysis}

The statistical tests of this study were computed with R software (The R Foundation, v. 3.5.2 "Eggshell Igloo"), basing the analysis on the base R commands and the library agricolae [29]. The significance level was set at $\alpha=0.05$. The arithmetic means and standard deviations of the biological triplicates were calculated. The different treatments were analyzed by one-way ANOVA paired with a Ryan-Einot-Gabriel-Welsch F (REGWF) post-hoc test. When the ANOVA assumptions were not met, a non-parametric Van der Waerden test was run, coupled with a least significant difference (LSD) post-hoc test. A principal component analysis (PCA) was also performed on the dataset of the aroma active compounds.

\section{Results and Discussion}

\subsection{Basic Chemical Parameters of the Wines}

In all of the cases, Sac. cerevisiae and Sch. pombe completely consumed the sugars in the grape juice that fermented at $20^{\circ} \mathrm{C}$. The Sac. cerevisiae fermentations finished the alcoholic fermentations in 8 days (without chitosan) and 11 days (with chitosan), while Sch. pombe required 28 and 34 days, respectively, (Figure 1) because of the slower fermentation kinetics of that species at low temperatures [2]. A previous study reported that $S c h$. pombe requires a longer fermentation period than the Sac. cerevisiae controls under similar conditions, varying from 17 to 20 additional days [30]. Other studies reported shorter fermentations times for Sch. pombe fermentations, but at higher temperatures of between 25 and $30{ }^{\circ} \mathrm{C}$ [2]. In these studies, the Sch. pombe fermentations were often slower than the Sac. cerevisiae controls after about 2 to 4 days. The studies usually emphasized that $S c h$. pombe wines did not require malolactic fermentation any more, which significantly reduced the total red wine production time [13]. The Sch. pombe fermentations produced more ethanol than Sac. cerevisiae, by about 0.2 to $0.4 \%(v / v$; Table 1$)$. The unique capacity of the Schizosaccharomcyes genus to convert malic acid into ethanol and $\mathrm{CO}_{2}$ is the reason for this [2]. This effect is clearer in the fermentation of raw materials 
that contain higher levels of malic acid than grapes, such as kei-apple, which possess up to $45 \mathrm{~g} / \mathrm{L}$ malic acid. Under these conditions, Sch. pombe produces alcoholic beverages with about $23 \%$ more ethanol than the Sac. cerevisiae control after fermenting all of the malic acid [6]. Some of the authors proposed the use of Sch. pombe in bioethanol production for its higher yield than Sac. cerevisiae [2]. The addition of chitosan did not influence the final ethanol concentration for Sch. pombe fermentations, and showed the same final concentration of $11.5 \%(v / v)$. Sac. cerevisiae produced $0.2 \%(v / v)$ less ethanol in the fermentation that contained chitosan.

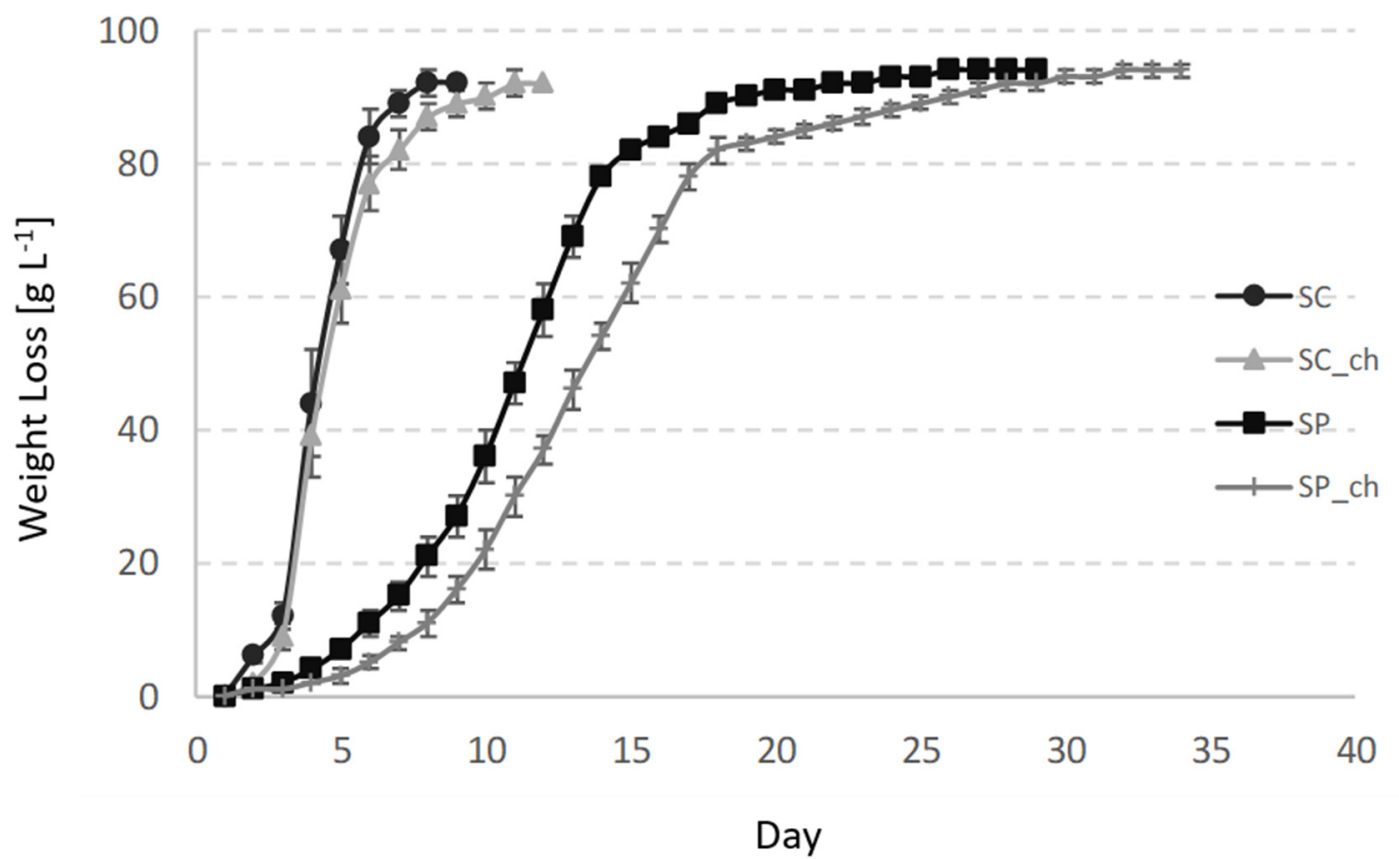

Figure 1. Fermentation kinetics of the variants measured gravimetrically by the total weight loss in the course of the fermentation. SC-Sac. Cerevisiae; SC_ch-Sac. cerevisiae fermenting with chitosan; $\mathrm{SP}-$ Sch. Pombe; SP_ch—Sch. pombe fermenting with chitosan. The values indicate the mean and standard deviations of the triplicates.

Table 1. Final analysis of the basic fermentative parameters-values from wines fermented with Sac. cerevisiae (SC), Sac. cerevisiae fermenting with chitosan (SC_ch), Sch. pombe (SP), and Sch. pombe fermenting with chitosan (SP_ch).

\begin{tabular}{|c|c|c|c|c|}
\hline Parameter & SC & SC_ch & SP & SP_ch \\
\hline Ethanol $[\% v / v]$ & $11.26 \pm 0.13^{b}$ & $11.08 \pm 0.01^{\mathrm{b}}$ & $11.52 \pm 0.06^{\mathrm{a}}$ & $11.52 \pm 0.09^{a}$ \\
\hline Residual Sugars $\left[\mathrm{g} \mathrm{L}^{-1}\right]$ & $<2$ & $<2$ & $<2$ & $<2$ \\
\hline Glucose $\left[\mathrm{g} \mathrm{L}^{-1}\right]$ & n.q. & n.q. & n.q. & n.q. \\
\hline Fructose $\left[\mathrm{g} \mathrm{L}^{-1}\right]$ & n.q. & n.q. & n.q. & n.q. \\
\hline Glycerol [g L ${ }^{-1}$ ] & $7.20 \pm 0.03^{c}$ & $8.48 \pm 0.14^{\mathrm{a}}$ & $7.74 \pm 0.17^{\mathrm{b}}$ & $8.54 \pm 0.41^{\mathrm{a}}$ \\
\hline Tartaric acid $\left[\mathrm{g} \mathrm{L}^{-1}\right]$ & $1.24 \pm 0.02^{\mathrm{a}}$ & $1.23 \pm 0.02^{\mathrm{a}}$ & $1.10 \pm 0.01^{b}$ & $1.28 \pm 0.06^{\mathrm{a}}$ \\
\hline L-Malic acid [g L $\left.{ }^{-1}\right]$ & $4.75 \pm 0.01^{\mathrm{a}}$ & $4.65 \pm 0.03^{b}$ & n.q. & n.q. \\
\hline Shikimic acid $\left[\mathrm{mg} \mathrm{L}^{-1}\right]$ & $8.32 \pm 0.09^{b}$ & $7.84 \pm 0.19^{b}$ & $8.27 \pm 0.05^{b}$ & $9.40 \pm 0.63^{a}$ \\
\hline L-Lactic acid $\left[\mathrm{g} \mathrm{L}^{-1}\right]$ & $0.18 \pm 0.01^{b}$ & $0.20 \pm 0.00^{\mathrm{a}, \mathrm{b}}$ & $0.21 \pm 0.00^{\mathrm{a}}$ & $0.20 \pm 0.02^{a, b}$ \\
\hline Acetic acid $\left[\mathrm{g} \mathrm{L}^{-1}\right]$ & $0.35 \pm 0.00^{\mathrm{a}}$ & $0.35 \pm 0.01^{\mathrm{a}}$ & $0.18 \pm 0.02^{c}$ & $0.28 \pm 0.02^{b}$ \\
\hline Citric acid $\left[\mathrm{g} \mathrm{L}^{-1}\right]$ & $0.16 \pm 0.01^{\mathrm{a}}$ & $0.16 \pm 0.01^{\mathrm{a}}$ & $0.17 \pm 0.02^{\mathrm{a}}$ & $0.16 \pm 0.03^{a}$ \\
\hline $\mathrm{pH}$ & $3.26 \pm 0.02^{b}$ & $3.22 \pm 0.02^{b}$ & $3.89 \pm 0.01^{\mathrm{a}}$ & $3.89 \pm 0.02^{\mathrm{a}}$ \\
\hline
\end{tabular}

The values indicate the mean and standard deviations of the fermentation triplicates; mean values in the same row with the same superscript letter are not significantly different from each other $(p<0.05)$; n.q. - not quantifiable.

The fermentations involving chitosan produced higher levels of glycerol. Sch. pombe produced $0.54 \mathrm{~g} \mathrm{~L}^{-1}$ more than Sac. cerevisiae made for the fermentations without chitosan. Some authors have suggested that Sch. pombe possesses a more developed glycerol-pyruvic pathway than Sac. cerevisiae, 
as beverages fermented by Sch. pombe often show higher levels of glycerol and pyruvic acid [13,31]. The Sac. cerevisiae fermentation enriched in chitosan produced $1.28 \mathrm{~g} \mathrm{~L}^{-1}$ more glycerol than the corresponding control. The Sch. pombe fermentation enriched in chitosan produced $0.8 \mathrm{~g} \mathrm{~L}^{-1}$ more glycerol than the control fermentation without chitosan.

Chitosan did not influence the final concentration of acetic acid for the Sac. cerevisiae fermentations, giving a final concentration of $0.35 \mathrm{~g} \mathrm{~L}^{-1}$. Previous studies reported that acetic acid has a slightly reduced final concentration $(0.08 \mathrm{~g} / \mathrm{L}$ lower) when chitosan performs as fining agent in wine [32]; however, that effect did not take place in this trial. Contrarily, chitosan increased the final acetic concentration of the $S c h$. pombe fermentations by about $0.1 \mathrm{~g} \mathrm{~L}^{-1}$. The final acetic acid concentrations in the Sch. pombe fermentation varied from 0.18 to $0.28 \mathrm{~g} \mathrm{~L}^{-1}$. All of the acetic acid concentrations were below the fault threshold of $0.8 \mathrm{~g} \mathrm{~L}^{-1}$ [29]. Although the Schizosaccharomyces genus can generate high concentrations of acetic acid over $1 \mathrm{~g} \mathrm{~L}^{-1}[2,6,8]$, modern strategies such as strain selection $[2,10]$ sequential fermentations with other yeast $[10,29]$, or fed-batch fermentation $[14,15]$ enable the control of this undesirable effect [2].

Sac. cerevisiae fermentations degraded about $20 \%$ of the initial malic acid concentration. A slightly higher reduction of $0.1 \mathrm{~g} \mathrm{~L}^{-1}$ took place in the fermentation that contained chitosan. Chitosan can also adsorb significant amounts of malic acid-up to $20 \%$ when it performs as a fining agent [32]. The fermentations involving Sch. pombe completely degraded the initial $6 \mathrm{~g} \mathrm{~L}^{-1}$ of malic acid. Sch. pombe provided an efficient biological method to de-acidify acidic grape juices with malic acid contents over $6 \mathrm{~g} / \mathrm{L}$ or other fruit juices with malic acid concentrations up to $45 \mathrm{~g} \mathrm{~L}^{-1}$ [6]. The degradation of malic acid influenced the final $\mathrm{pH}$ of wine, which varied from $\mathrm{pH} 3.22$ for Sac. cerevisiae fermentations to $\mathrm{pH} 3.89$ for Sch. pombe fermentations. Previous studies reported $\mathrm{pH}$ variations lower than about 0.1 when the malic acid initial content was below $1 \mathrm{~g} / \mathrm{L}[2,13]$, and higher variations in a $\mathrm{pH}$ of about 0.9 for fruit with malic acid contents over $10 \mathrm{~g} / \mathrm{L}$ [6].

The Sac. cerevisiae fermentations treated with chitosan showed a slightly lower final concentration of shikimic acid, by $0.48 \mathrm{mg} / \mathrm{L}$ compared with the Sac. cerevisiae control fermentation without chitosan, although no significant differences were observed (Table 1). Chitosan was able to adsorb shikimic acid similarly to that reported for malic acid [32]. Fermentations involving Sch. pombe showed the opposite effect, with an increase of about $1.1 \mathrm{mg} / \mathrm{L}$ for the fermentations treated with chitosan.

Previous studies reported a significant deacidification capacity for chitosan in fruit juices other than grape juice. The effect is because of chitosan interacting with organic acids [20]. In the present work, although slight differences in some organic acids took place, chitosan did not have statistically significant differences in the final $\mathrm{pH}$.

The Sch. pombe fermentations produced higher final concentrations of acetaldehyde than the Sac. cerevisiae fermentations (Figure 2). Chitosan influenced the production of acetaldehyde. In the case of Sac. cerevisiae, a slight decrease of $2.5 \mathrm{mg} \mathrm{L}^{-1}$ took place for the fermentations enriched with chitosan. In the case of Sch. pombe, the production of acetaldehyde increased from 28.6 to $47.6 \mathrm{mg}$ $\mathrm{L}^{-1}$ in the presence of chitosan. Nevertheless, all of the acetaldehyde concentrations were below the fault aroma threshold of $125 \mathrm{mg} \mathrm{L}^{-1}$ [33,34]. Acetaldehyde production by members of the genus Schizosaccharomyces widely differ, depending on the strain, with reported values ranging from $16.46 \mathrm{mg}$ $\mathrm{L}^{-1}$ to $134.14 \mathrm{mg} \mathrm{L}^{-1}[2,4,9]$. A moderately high production of acetaldehyde below the fault threshold of $125 \mathrm{mg} \mathrm{L}^{-1}$ is of interest in the production of red wine, as it increases the content of one of the most stable anthocyanins, known as Vitisin B [2,13]. However, in white wine production, an excess of acetaldehyde may promote undesirable aromas, such as green apples or fresh-cut grass [13,33]. Using fed-batch technology during the alcoholic fermentation for white wine production reduces the production of acetaldehyde by Sch. pombe by $50 \%$ [14]. 

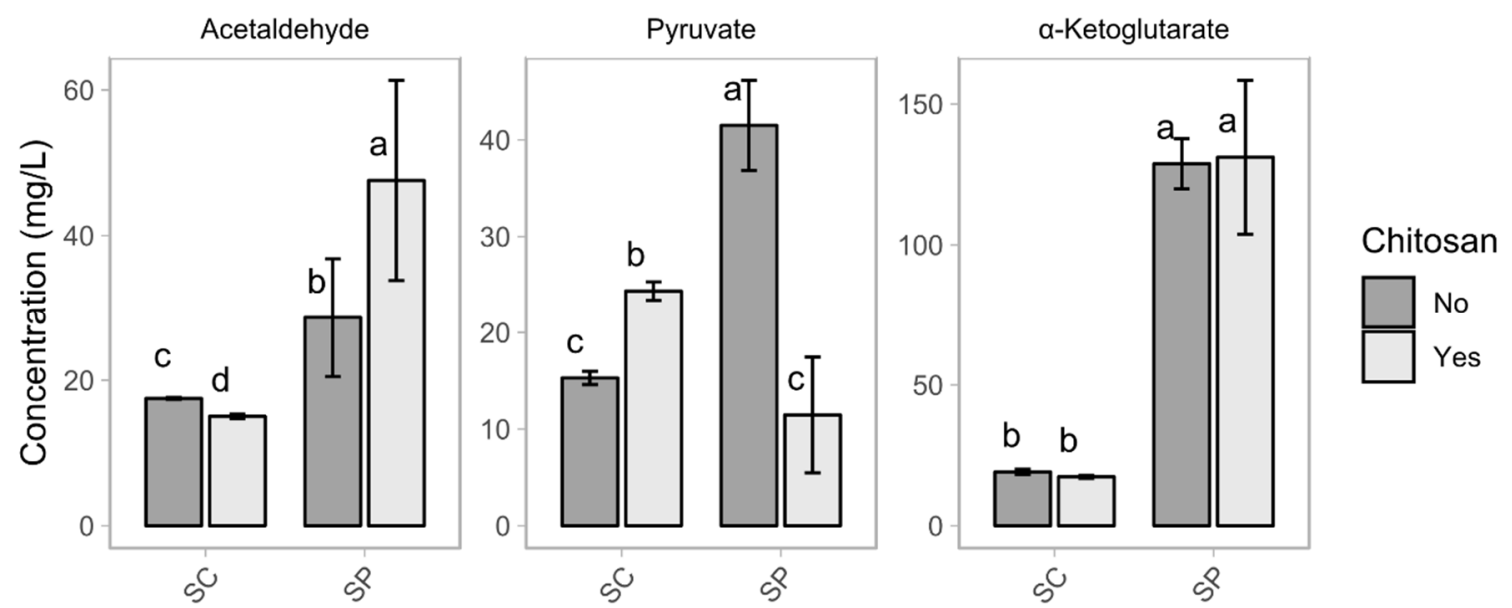

Figure 2. Plot of the concentrations of acetaldehyde, pyruvate, and $\alpha$-ketoglutarate in the wines showing the variable yeast (SC and SP) and the variable chitosan (no and yes). The bars report the mean value and standard deviation. Within each plot, the same letters indicate a non-statistical difference between the mean values.

Chitosan influenced the production of pyruvic acid for the two species. The effect was an increase of about $59.4 \%$ in the case of Sac. cerevisiae, with concentrations that varied from $15.3 \mathrm{mg} \mathrm{L}^{-1}$ (SC) to $24.4 \mathrm{mg} \mathrm{L}^{-1}$ (SC_ch). However, the effect was a decrease of about $72.4 \%$ for fermentations by Sch. pombe, in which the final concentrations varied from $41.5 \mathrm{mg} \mathrm{L}^{-1}$ (SP) to $11.5 \mathrm{mg} \mathrm{L}^{-1}$ (SP_ch). Sch. pombe is the highest pyruvic acid producer among fermentative yeasts, able to reach concentrations four times higher than the Sac. cerevisiae controls $[2,13,31]$.

Chitosan did not influence the production of $\alpha$-ketoglutarate. The Sch. pombe fermentations produced final concentrations of $\alpha$-ketoglutarate of about $128.8 \mathrm{mg} \mathrm{L}^{-1}$ (SP) and $131.1 \mathrm{mg} \mathrm{L}^{-1}$ (SP_ch), while the Sac. cerevisiae fermentations produced final concentrations of about $19.1 \mathrm{mg} \mathrm{L}^{-1}$ (SC) and $17.1 \mathrm{mg} \mathrm{L}^{-1}$ (SC_ch).

\subsection{Volatile Compounds}

Some non-conventional yeasts can improve wine aroma complexity because of their influence over higher alcohols, esters, and terpenes [35-39]. Previous studies reported that selected Sch. pombe strains produce lower concentrations of higher alcohols than the Sac. cerevisiae controls, varying from $25 \%$ to $77 \%$ depending on the studied higher alcohol $[2,10]$. Reducing the production of higher alcohols is a modern strategy to avoid masking desirable varietal aromas [33]. The present study observed a reduction of about $50 \%$ of total higher alcohols for Sch. pombe fermentations compared with the Sac. cerevisiae controls (Table 2). Sch. pombe produced lower isoamyl alcohol, 2-phenylethyl alcohol, and isobutanol than the Sac. cerevisiae control by $56.0 \%, 64.3 \%$, and $26.7 \%$, respectively. Chitosan did not significantly influence higher alcohol production for the Sac. cerevisiae fermentations. In the case of Sch. pombe, the chitosan fermentations produced significantly lower levels of isoamyl alcohol and 2-phenyl alcohol. Other studies reported that chitosan can remove significant amounts of 4-ethylphenol and 4-ethylguaiacol from red wine, varying from 7 to $25 \%$ depending on the dose [40]. 
Table 2. Volatile compounds measured after the fermentation of Sac. cerevisiae (SC), Sac. cerevisiae fermenting with chitosan (SC_ch), Sch. pombe (SP), and Sch. pombe fermenting with chitosan (SP_ch).

\begin{tabular}{|c|c|c|c|c|}
\hline Volatile Compound & SC & SC_ch & SP & SP_ch \\
\hline \multicolumn{5}{|l|}{ Acetate Esters } \\
\hline Ethyl Acetate $\left[\mathrm{mg} \mathrm{L}^{-1}\right.$ ] & $169.8 \pm 9.6^{b}$ & $187.0 \pm 1.2^{\mathrm{a}}$ & $163.6 \pm 5.3^{b}$ & $117.2 \pm 5.5^{c}$ \\
\hline Isoamyl acetate $\left[\mu \mathrm{g} \mathrm{L}^{-1}\right]$ & $7813.4 \pm 374.3^{b}$ & $11,301.5 \pm 1197.0^{a}$ & $6350.6 \pm 286.3^{b}$ & $3217.3 \pm 1643.5^{c}$ \\
\hline 2-Methyl butyl acetate $\left[\mu \mathrm{g} \mathrm{L}^{-1}\right]$ & $261.1 \pm 10.7^{\mathrm{a}}$ & $280.3 \pm 9.1^{\mathrm{a}}$ & $254.0 \pm 9.6^{\mathrm{a}}$ & $182.5 \pm 43.4^{\mathrm{b}}$ \\
\hline Hexyl acetate $\left[\mu \mathrm{g} \mathrm{L}^{-1}\right]$ & $88.1 \pm 4.9^{\mathrm{a}}$ & $98.5 \pm 10.4^{a}$ & $31.0 \pm 2.4^{b}$ & n.q. \\
\hline 2-Phenyl ethyl acetate $\left[\mu \mathrm{g} \mathrm{L}^{-1}\right]$ & $330.5 \pm 4.0^{b}$ & $453.4 \pm 36.4^{\mathrm{a}}$ & $123.1 \pm 11.6^{c}$ & $66.6 \pm 30.3^{d}$ \\
\hline$\Sigma$ Acetates $\left[\mu \mathrm{g} \mathrm{L}^{-1}\right]$ & $178,293.1$ & $199,133.7$ & $170,358.7$ & $15,186.4$ \\
\hline \multicolumn{5}{|l|}{ Ethyl Esters } \\
\hline Ethyl propionate $\left[\mu \mathrm{g} \mathrm{L}^{-1}\right]$ & $170.1 \pm 4.5^{b}$ & $187.4 \pm 4.5^{\mathrm{a}}$ & $93.6 \pm 12.1^{\mathrm{d}}$ & $128.9 \pm 5.1^{\mathrm{c}}$ \\
\hline Ethyl butyrate $\left[\mu \mathrm{g} \mathrm{L}^{-1}\right]$ & $552.6 \pm 12.1^{a}$ & $562.1 \pm 53.7^{\mathrm{a}}$ & $657.8 \pm 16.6^{\mathrm{a}}$ & $377.7 \pm 102.5^{b}$ \\
\hline Ethyl isobutyrate $\left[\mu \mathrm{g} \mathrm{L}^{-1}\right]$ & $39.7 \pm 3.4^{\mathrm{a}}$ & $41.4 \pm 3.2^{\mathrm{a}}$ & $20.3 \pm 1.6^{c}$ & $30.1 \pm 5.9^{b}$ \\
\hline Ethyl hexanoate $\left[\mu \mathrm{g} \mathrm{L}^{-1}\right]$ & $907.1 \pm 16.0^{\mathrm{a}, \mathrm{b}}$ & $1006.2 \pm 103.1^{a}$ & $777.0 \pm 49.7^{b, c}$ & $637.7 \pm 64.7^{c}$ \\
\hline Ethyl octanoate $\left[\mu \mathrm{g} \mathrm{L}^{-1}\right]$ & $1354.4 \pm 26.6^{\mathrm{a}}$ & $1293.8 \pm 48.9^{a}$ & $917.6 \pm 68.4^{b}$ & $749.2 \pm 196.5^{b}$ \\
\hline Ethyl decanoate $\left[\mu \mathrm{g} \mathrm{L}^{-1}\right]$ & $464.1 \pm 4.7^{\mathrm{a}}$ & $430.6 \pm 28.6^{a}$ & $281.3 \pm 26.0^{b}$ & $162.8 \pm 59.5^{c}$ \\
\hline$\Sigma$ Ethyl esters $\left[\mu \mathrm{g} \mathrm{L}^{-1}\right]$ & 3488.0 & 3521.5 & 2747.6 & 2086.4 \\
\hline \multicolumn{5}{|l|}{ Higher Alcohols } \\
\hline Isobutanol $\left[\mathrm{mg} \mathrm{L}^{-1}\right]$ & $28.8 \pm 0.5^{b}$ & $32.0 \pm 1.3^{\mathrm{a}}$ & $20.6 \pm 1.2^{d}$ & $24.0 \pm 2.5^{\mathrm{c}}$ \\
\hline Isoamyl alcohol [mg L $\left.\mathrm{m}^{-1}\right]$ & $243.7 \pm 7.8^{a}$ & $255.1 \pm 7.4^{\mathrm{a}}$ & $126.2 \pm 5,7^{b}$ & $93.3 \pm 7.5^{c}$ \\
\hline Active amyl alcohol $\left[\mathrm{mg} \mathrm{L}^{-1}\right]$ & $22.4 \pm 0.2^{a, b}$ & $26.3 \pm 0.4^{\mathrm{a}}$ & $19.3 \pm 2.2^{b}$ & $21.6 \pm 2.3^{b}$ \\
\hline Hexanol $\left[\mu \mathrm{g} \mathrm{L}^{-1}\right]$ & n.q. & n.q. & n.q. & n.q. \\
\hline 2-Phenyl-ethanol [mg L ${ }^{-1}$ ] & $18.6 \pm 0.9^{b}$ & $22.0 \pm 0.5^{\mathrm{a}}$ & $7.9 \pm 0.4^{c}$ & $6.6 \pm 0.4^{\mathrm{d}}$ \\
\hline$\Sigma$ Higher alcohols $\left[\mathrm{mg} \mathrm{L}^{-1}\right]$ & 313.5 & 335.4 & 174 & 145.5 \\
\hline \multicolumn{5}{|l|}{ Fatty Acids } \\
\hline Isovaleric acid $\left[\mu \mathrm{g} \mathrm{L}^{-1}\right]$ & $2526.2 \pm 103.2^{a}$ & $2620.7 \pm 53.0^{\mathrm{a}}$ & $2040.2 \pm 7.4^{b}$ & $1768.6 \pm 18.3^{c}$ \\
\hline Hexanoic acid $\left[\mathrm{mg} \mathrm{L}^{-1}\right]$ & $12.9 \pm 0.7^{a}$ & $12.9 \pm 0.4^{\mathrm{a}}$ & $12.1 \pm 0.6^{\mathrm{a}}$ & $10.6 \pm 0.5^{\mathrm{b}}$ \\
\hline Octanoic acid [mg L $\left.{ }^{-1}\right]$ & $10.8 \pm 0.5^{\mathrm{a}}$ & $11.0 \pm 0.5^{a}$ & $7.9 \pm 0.6^{b}$ & $6.3 \pm 1.0^{\mathrm{b}}$ \\
\hline Decanoic acid $\left[\mathrm{mg} \mathrm{L}^{-1}\right]$ & $3.1 \pm 0.1^{\mathrm{a}}$ & $3.0 \pm 0.2^{\mathrm{a}}$ & $2.3 \pm 0.2^{b}$ & $1.8 \pm 0.4^{\mathrm{c}}$ \\
\hline$\Sigma$ Fatty acids $\left[\mathrm{mg} \mathrm{L}^{-1}\right]$ & 29.3 & 29.5 & 24.3 & 20.5 \\
\hline \multicolumn{5}{|l|}{$\begin{array}{l}\text { Monoterpenoids and } \\
\mathrm{C}_{13} \text {-norisoprenoids }\end{array}$} \\
\hline Linalool oxide- $1\left[\mu \mathrm{g} \mathrm{L}^{-1}\right]$ & $5.4 \pm 0.5^{b}$ & $5.9 \pm 0.6^{b}$ & $6.0 \pm 0.3^{b}$ & $7.2 \pm 0.2^{a}$ \\
\hline
\end{tabular}

The values indicate the mean and standard deviation of the fermentation triplicates; mean values in the same row with the same letter are not significantly different from each other $(p<0.05)$; n.q.- - not quantifiable.

Schizosaccharomyces fermentations produced a lower concentration of esters than those of Sac. cerevisiae, with the effect being especially noteworthy for the ethyl esters family where the observed reduction was $22 \%$ (Table 2). Previous studies reported reductions in ester production by Sch. pombe compared with the Sac. cerevisiae controls, with the effect varying from 15 to $35 \%$, depending on the studied ester $[2,10]$. Chitosan stimulated the production of acetate esters such as isoamyl acetate and phenyl ethyl acetate by $44.6 \%$ and $37.2 \%$, respectively, for Sac. cerevisiae. The opposite effect took place for Sch. pombe, with chitosan causing a $28.4 \%$ reduction in ethyl acetate, a $49.3 \%$ reduction in isoamyl acetate, a $28.2 \%$ reduction in 2-methylbutyl acetate, and a $45.9 \%$ reduction in phenyl acetate. It was not possible to quantify hexyl acetate in the Sch. pombe fermentation enriched with chitosan.

Chitosan did not influence the final concentration of ethyl esters for the fermentations with Sac. cerevisiae. Other studies reported reductions in some esters, such as methyl and ethyl octanoate, showing about a 30\% reduction when chitosan performs as a fining agent [32]. In the case of Sch. pombe, the chitosan trials showed higher final concentrations in ethyl isobutyrate $(47.8 \%)$ and ethyl propionate $(27.39 \%)$, while they showed lower concentrations of ethyl butyrate ( $42.6 \%$ reduction), ethyl hexanoate ( $17.9 \%$ reduction), and ethyl decanoate $(42.1 \%$ reduction).

Sch. pombe produced less fatty acids than Sac. cerevisiae for all of the fatty acids included in our study. The biggest differences took place for isovaleric, octanoic, and decanoic acids (with reductions of $26.0 \%, 34.9 \%$, and $34.2 \%$, respectively). Chitosan did not influence the final concentration of fatty acids in the case of Sac. cerevisiae, while some fatty acid concentrations decreased in the Sch. pombe fermentations, such as isovaleric acid (13.3\% reduction), hexanoic acid (12.3\% reduction), and decanoic acid (23.0\% reduction). 
Previous studies reported significant reductions (up to 70\%) in terpene concentrations when chitosan performed as a fining agent in a terpenic grape variety [32]. Chitosan rarely affected the other aroma compounds. In the present study, although the wines did not show a high content in the terpenes, a statistically significant increase of $1.2 \mu \mathrm{g} / \mathrm{L}$ terpenes took place for the Sch. pombe fermentations containing chitosan.

The PCA in Figure 3 shows the lower overall contribution of Sch. pombe to the final fermentation aroma compared with Sac. cerevisiae. Sac. cerevisiae differs from Sch. pombe because of the increased production of aroma-active compounds. The PCA also highlights the different behavior of yeasts in the presence of chitosan. Chitosan shows a slight effect on the composition of the Sac. cerevisiae aroma compounds, which does not affect the final fermentation aroma because the variants are closely grouped. However, in the case of Sch. pombe, the variant fermented with chitosan separated from the one without because of a lower aroma production.

A

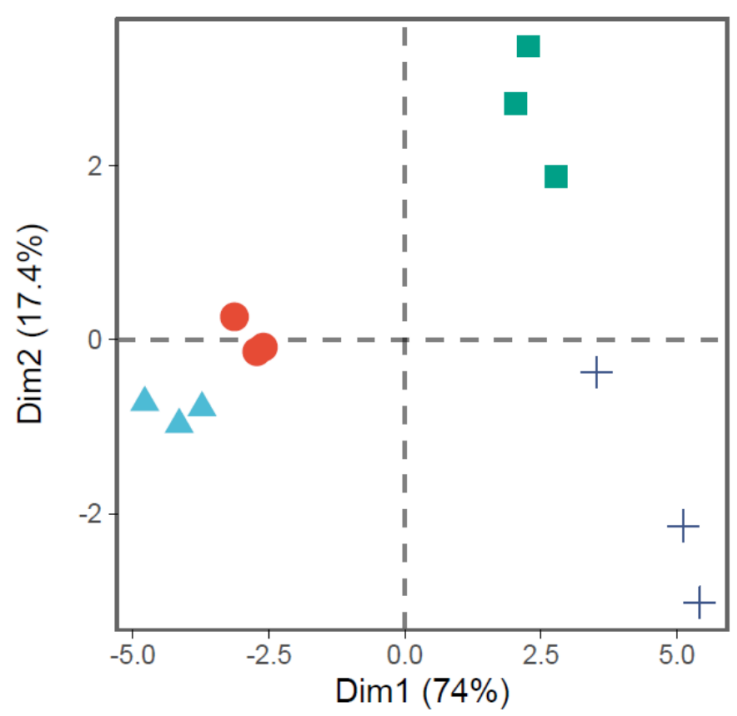

SC $\triangle$ SC_ch $\square$ SP + SP_ch
B

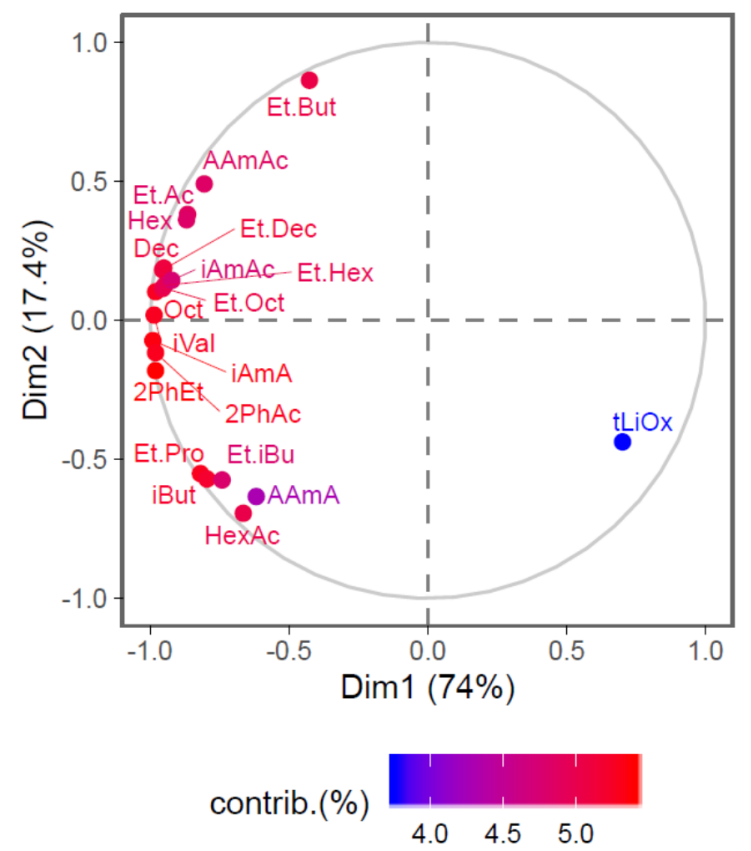

Figure 3. Principal component analysis of the microbial metabolic contribution to the aroma of the wines. (A) The plot of the fermentation treatments in the two principal dimensions (Dim1 and Dim2), which indicates $91.7 \%$ of the variance in the data. (B) The plot of the first 15 variables with the highest contribution on the explained variance between treatments in the two dimensions is presented in a continuous scale of colors that show the lowest contribution (blue) to the highest (red). Abbreviations: Ethyl acetate (Et.Ac), Isobutanol (iBut), Ethyl propionate (Et.Pro), Isoamyl alcohol (iAmA), Active amyl alcohol (AAmA), Ethyl isobutyrate (Et.iBu), Ethyl butyrate (Et.But), Isovaleric acid (iVal), Isoamyl acetate (iAmAc), Active amyl acetate (AAmAc), Hexanoic acid (Hex), Ethyl hexanoate (Et.Hex), Hexyl acetate (HexAc), trans-Linalool oxide (tLiOx), 2-Phenylethanol (2PhEt), Octanoic acid (Oct), Ethyl octanoate (Et.Oct), 2-Phenylethyl acetate (2PhAc), Decanoic acid (Dec), and Ethyl decanoate (Et.Dec).

\section{Conclusions}

Chitosan is an important tool for controlling oxidation and undesirable microbial development during fermentation and wine ageing. Our findings show that chitosan influences the final chemical composition of wine fermented with Sac. cerevisiae and Sch. pombe, including the contents of acetic acid, ethanol, glycerol, acetaldehyde, pyruvic acid, $\alpha$-ketoglutarate, higher alcohols, acetate esters, ethyl esters, and volatile fatty acids. The results of the study also show that Sch. pombe produces higher concentrations of glycerol, acetaldehyde, pyruvate, and $\alpha$-ketoglutarate than the Sac. cerevisiae 
control. Contrarily, the selected Sch. pombe strain produced lower levels of acetic acid, malic acid, higher alcohols, ethyl esters, and fatty acids.

Author Contributions: D.R., S.B. (Santiago Benito) and S.S. developed the experimental design; S.S. and S.B. (Santiago Benito) performed the vinifications; S.S. and S.B. (Santiago Benito) performed the formal data analysis and supervised the project; S.S., S.B. (Santiago Benito) and D.R. wrote the article; S.B. (Silvia Brezina) performed the gas chromatographic analysis; H.S. and S.S. performed the HPLC analysis. All of the authors discussed the results and contributed to the final manuscript. All authors have read and agreed to the published version of the manuscript.

Funding: Funding for Santiago Benito was provided by Ossian Vides y Vinos S. L, under the framework of project FPA1720300120 (Centre for the Development of Industrial Technology (CDTI), Spain). This project was co-funded by the Erasmus+ program of the European Union.

Conflicts of Interest: The authors declare no conflict of interest.

\section{References}

1. Jolly, N.P.; Varela, C.; Pretorius, I.S. Not your ordinary yeast: Non-Saccharomyces yeasts in wine production uncovered. FEMS Yeast Res. 2014, 14, 215-217. [CrossRef]

2. Benito, S. The impacts of Schizosaccharomyces on winemaking. Appl. Microbiol. Biotechnol. 2019, 103, 4291-4312. [CrossRef]

3. Vilela, A. Use of Nonconventional Yeasts for Modulating Wine Acidity. Fermentation 2019, 5, 27. [CrossRef]

4. Liu, S.; Laaksonen, O.; Kortesniemi, M.; Kalpio, M.; Yang, B. Chemical composition of bilberry wine fermented with non-Saccharomyces yeasts (Torulaspora delbrueckii and Schizosaccharomyces pombe) and Saccharomyces cerevisiae in pure, sequential and mixed fermentations. Food Chem. 2018, 266, 262-274. [CrossRef]

5. Liu, S.; Laaksonen, O.; Yang, B. Volatile composition of bilberry wines fermented with non-Saccharomyces and Saccharomyces yeasts in pure, sequential and simultaneous inoculations. Food Microbiol. 2019, 80, 25-39. [CrossRef] [PubMed]

6. Minnaar, P.; Jolly, N.; Paulsen, V.; Du Plessis, H.; Van Der Rijst, M. Schizosaccharomyces pombe and Saccharomyces cerevisiae yeasts in sequential fermentations: Effect on phenolic acids of fermented Kei-apple (Dovyalis caffra L.) juice. Int. J. Food Microbiol. 2017, 257, 232-237. [CrossRef] [PubMed]

7. Satora, P.; Semik-Szczurak, D.; Tarko, T.; Bułdys, A. Influence of Selected Saccharomyces and Schizosaccharomyces Strains and Their Mixed Cultures on Chemical Composition of Apple Wines. J. Food Sci. 2018, 83, 424-431. [CrossRef] [PubMed]

8. Miljić, U.D.; Puškaš, V.; Vučurović, V.; Muzalevski, A. Fermentation Characteristics and Aromatic Profile of Plum Wines Produced with Indigenous Microbiota and Pure Cultures of Selected Yeast. J. Food Sci. 2017, 47, 1139-1450. [CrossRef] [PubMed]

9. Domizio, P.; Lencioni, L.; Calamai, L.; Portaro, L.; Bisson, L.F. Evaluation of the Yeast Schizosaccharomyces japonicus for Use in Wine Production. Am. J. Enol. Vitic. 2018, 69, 266-277. [CrossRef]

10. Benito, Á; Calderón, F.; Benito, S. Combined Use of S. pombe and L. thermotolerans in Winemaking. Beneficial Effects Determined through the Study of Wines' Analytical Characteristics. Molecules 2016, $21,1744$. [CrossRef] [PubMed]

11. Vilela, A. Lachancea thermotolerans, the Non-Saccharomyces yeast that reduces the volatile acidity of wines. Fermentation 2018, 4, 56. [CrossRef]

12. Porter, T.J.; Divol, B.; Setati, M.E. Lachancea yeast species: Origin, biochemical characteristics and oenological significance. Food Res. Int. 2019, 119, 378-389. [CrossRef] [PubMed]

13. Benito, S. Combined Use of Lachancea thermotolerans and Schizosaccharomyces pombe in Winemaking: A Review. Microorganisms 2020, 8, 655. [CrossRef]

14. Roca-Domènech, G.; Cordero-Otero, R.; Rozès, N.; Cléroux, M.; Pernet, A.; De Orduña, R.M. Metabolism of Schizosaccharomyces pombe under reduced osmotic stress conditions afforded by fed-batch alcoholic fermentation of white grape must. Food Res. Int. 2018, 113, 401-406. [CrossRef]

15. Scomparin, A.; Bureik, M. A convenient new method for reproducible fed-batch fermentation of fission yeast Schizosaccharomyces pombe. Biotechnol. Lett. 2020, 42, 937-943. [CrossRef] [PubMed] 
16. Domizio, P.; Liu, Y.; Bisson, L.; Barile, D. Cell Wall Polysaccharides Released during the Alcoholic Fermentation by Schizosaccharomyces Pombe and S. Japonicus: Quantification and Characterization. Food Microbiol. 2017, 61, 136-149. [CrossRef] [PubMed]

17. Benito, Á.; Calderón, F.; Benito, S. Mixed alcoholic fermentation of Schizosaccharomyces pombe and Lachancea thermotolerans and its influence on mannose-containing polysaccharides wine Composition. $A M B$ Express 2019, 9, 17. [CrossRef]

18. Benito, S. The Management of Compounds that Influence Human Health in Modern Winemaking from an HACCP Point of View. Fermentation 2019, 5, 33. [CrossRef]

19. Vilela, A. Non-Saccharomyces Yeasts and Organic Wines Fermentation: Implications on Human Health. Fermentation 2020, 6, 54. [CrossRef]

20. Bornet, A.; Teissedre, P.-L. Chitosan, chitin-glucan and chitin effects on minerals (iron, lead, cadmium) and organic (ochratoxin A) contaminants in wines. Eur. Food Res. Technol. 2008, 226, 681-689. [CrossRef]

21. Bağder Elmaci, S.; Gülgör, G.; Tokatli, M.; Erten, H.; İşci, A.; Özçelik, F. Effectiveness of chitosan against wine-related microorganisms. Antonie v. Leeuwenh. 2015, 107, 675-686. [CrossRef]

22. Escudero-Abarca, B.I.; Aguilar-Uscanga, M.G.; Hayward-Jones, P.M.; Mendoza, P.; Gómez-Rivas, L.; Ramírez, M. Selective antimicrobial action of chitosan against spoilage yeasts in mixed culture fermentations. J. Ind. Microbiol. Biotechnol. 2004, 31, 16-22. [CrossRef] [PubMed]

23. Petrova, B.; Cartwright, Z.M.; Edwards, C.G. Effectiveness of chitosan preparations against Brettanomyces bruxellensis grown in culture media and red wines. OENO ONE 2016, 50, 49. [CrossRef]

24. Valera, M.J.; Sainz, F.; Mas, A.; Torija, M.J. Effect of chitosan and $\mathrm{SO}_{2}$ on viability of Acetobacter strains in wine. Int. J. Food Microbiol. 2017, 246, 1-4. [CrossRef] [PubMed]

25. Picariello, L.; Rinaldi, A.; Blaiotta, G.; Moio, L.; Pirozzi, P.; Gambuti, A. Effectiveness of chitosan as an alternative to sulfites in red wine production. Eur. Food Res. Technol. 2020, 246, 1795-1804. [CrossRef]

26. Kanter, J.P.; Benito, S.; Brezina, S.; Beisert, B.; Fritsch, S.; Patz, C.D.; Rauhut, D. The impact of hybrid yeasts on the aroma profile of cool climate Riesling wines. Food Chem. X 2020, 5, 100072. [CrossRef] [PubMed]

27. Mecca, D.; Benito, S.; Beisert, B.; Brezina, S.; Fritsch, S.; Semmler, H.; Rauhut, D. Influence of Nutrient Supplementation on Torulaspora Delbrueckii Wine Fermentation Aroma. Fermentation 2020, 6, 35. [CrossRef]

28. Bergmeyer, H.U. From the Preface to the 1st Edition. In Methods of Enzymatic Analysis; Elsevier BV: Amsterdam, The Netherlands, 1974. [CrossRef]

29. De Mendiburu, F. Package "Agricolae: Statistical Procedures for Agricultural Research". 2020. Available online: https://cran.r-project.org/web/packages/agricolae/agricolae.pdf (accessed on 5 October 2020).

30. Du Plessis, H.; Hoff, J.; Hart, R.; Ndimba, B.; Jolly, N.; Du Toit, M. Characterisation of Non-Saccharomyces Yeasts Using Different Methodologies and Evaluation of their Compatibility with Malolactic Fermentation. S. Afr. J. Enol. Vitic. 2017, 38, 46-63. [CrossRef]

31. Liu, S.; Laaksonen, O.; Yang, W.; Zhang, B.; Yang, B. Pyranoanthocyanins in bilberry (Vaccinium myrtillus L.) wines fermented with Schizosaccharomyces pombe and their evolution during aging. Food Chem. 2020, 305, 125438. [CrossRef]

32. Colangelo, D.; Torchio, F.; De Faveri, D.M.; Lambri, M. The use of chitosan as alternative to bentonite for wine fining: Effects on heat-stability, proteins, organic acids, colour, and volatile compounds in an aromatic white wine. Food Chem. 2018, 264, 301-309. [CrossRef]

33. Ruiz, J.; Kiene, F.; Belda, I.; Fracassetti, D.; Marquina, D.; Navascués, E.; Calderón, F.; Benito, A.; Rauhut, D.; Santos, A.; et al. Effects on varietal aromas during wine making: A review of the impact of varietal aromas on the flavor of wine. Appl. Microbiol. Biotechnol. 2019, 103, 7425-7450. [CrossRef] [PubMed]

34. Song, Z.; Du, H.; Zhang, M.; Nie, Y.; Xu, Y. Schizosaccharomyces pombe Can Reduce Acetic Acid Produced by Baijiu Spontaneous Fermentation Microbiota. Microorganisms 2019, 7, 606. [CrossRef] [PubMed]

35. Gamero, A.; Manzanares, P.; Querol, A.; Belloch, C. Monoterpene alcohols release and bioconversion by Saccharomyces species and hybrids. Int. J. Food Microbiol. 2011, 145, 92-97. [CrossRef]

36. Stribny, J.; Gamero, A.; Pérez-Torrado, R.; Querol, A. Saccharomyces kudriavzevii and Saccharomyces uvarum differ from Saccharomyces cerevisiae during the production of aroma-active higher alcohols and acetate esters using their amino acidic precursors. Int. J. Food Microbiol. 2015, 205, 41-46. [CrossRef] 
37. Roudil, L.; Russo, P.; Berbegal, C.; Albertin, W.; Spano, G.; Capozzi, V. Non-Saccharomyces Commercial Starter Cultures: Scientific Trends, Recent Patents and Innovation in the Wine Sector. Recent Pat. Food Nutr. Agric. 2019, 10, 1. [CrossRef]

38. Gamero, A.; Quintilla, R.; Groenewald, M.; Alkema, W.; Boekhout, T.; Hazelwood, L. High-throughput screening of a large collection of non-conventional yeasts reveals their potential for aroma formation in food fermentation. Food Microbiol. 2016, 60, 147-159. [CrossRef] [PubMed]

39. Berbegal, C.; Fragasso, M.; Russo, P.; Bimbo, F.; Grieco, F.; Spano, G.; Capozzi, V. Climate changes and food quality: The potential of microbial activities as mitigating strategies in the wine sector. Fermentation 2019, 5, 85. [CrossRef]

40. Filipe-Ribeiro, L.; Cosme, F.; Nunes, F.M. Reducing the negative sensory impact of volatile phenols in red wine with different chitosans: Effect of structure on efficiency. Food Chem. 2018, 242, 591-600. [CrossRef]

(C) 2020 by the authors. Licensee MDPI, Basel, Switzerland. This article is an open access article distributed under the terms and conditions of the Creative Commons Attribution (CC BY) license (http://creativecommons.org/licenses/by/4.0/). 